\title{
Quantification of surface species present on a nickel/alumina methane reforming catalyst $\dagger$
}

\author{
Ian P. Silverwood, ${ }^{a}$ Neil G. Hamilton, ${ }^{a}$ Christian J. Laycock, ${ }^{b}$ John Z. Staniforth, ${ }^{b}$ \\ R. Mark Ormerod, ${ }^{b}$ Christopher D. Frost, ${ }^{c}$ Stewart F. Parker ${ }^{c}$ and David Lennon* ${ }^{* a}$
}

Received 24th September 2009, Accepted 11th February 2010

First published as an Advance Article on the web 24th February 2010

DOI: $10.1039 / b 919977 b$

\begin{abstract}
An alumina-supported nickel catalyst has been used to effect the 'dry' reforming of methane, using $\mathrm{CO}_{2}$ as the oxidant. After 6 hours on-stream, reaction was stopped and the sample analysed by inelastic neutron scattering (INS). The INS spectrum reveals the presence of hydrocarbonaceous species as well as hydroxyl species present at the catalyst surface. Through the use of appropriate reference compounds, calibration procedures have been developed to determine the concentration of the retained hydrocarbon and hydroxyl moieties. Ancillary temperature programmed oxidation experiments establish the total carbon content. This approach not only enables the extent of overall carbon laydown to be determined but it also identifies the degree to which hydrogen is associated with carbon and oxygen atoms. The methodology described is generic and should be applicable to a wide number of heterogeneously catalysed systems.
\end{abstract}

\section{Introduction}

The reforming of methane to synthesis gas $\left(\mathrm{CO}+\mathrm{H}_{2}\right)$ continues to be an economically important reaction, not least because it provides two reagents that can be used in a wide range of chemical processes. ${ }^{1}$ The breadth of the options available is encompassed within the concept of a methane refinery. ${ }^{2}$ Whereas industry currently favours the steam reforming process, ${ }^{3}$ interest is growing in the 'dry' reforming variant where $\mathrm{CO}_{2}$ is used as the oxidant. Potential applications for 'dry' reforming include hydrogen production from biomass gasification ${ }^{4,5}$ and feedstock production for Fischer Tröpsch synthesis, ${ }^{6}$ where the $\mathrm{H}_{2}$ : $\mathrm{CO}$ ratio produced by dry reforming is more favourable than that produced by steam reforming.

In principle, the chemical equation for the 'dry' reforming reaction is inherently simple (eqn (1))

$$
\mathrm{CH}_{4}+\mathrm{CO}_{2} \rightarrow 2 \mathrm{CO}+2 \mathrm{H}_{2}
$$

\footnotetext{
${ }^{a}$ Department of Chemistry, Joseph Black Building,

University of Glasgow, Glasgow, G12 8QQ, Scotland, UK.

E-mail: d.lennon@chem.gla.ac.uk; Fax: +44-(0)141-330-4888, Tel: + 44-(0)141-330-4372

${ }^{b}$ School of Physical \& Geographical Sciences, Keele University, Staffs, ST5 5BG, UK

${ }^{c}$ ISIS Facility, Rutherford Appleton Laboratory, Chilton, Didcot, Oxon OX11 0QX, UK

$\dagger$ Electronic supplementary information (ESI) available: Inelastic neutron scattering spectra of talc $\left(\mathrm{Mg}_{3} \mathrm{Si}_{4} \mathrm{O}_{10}(\mathrm{OH})_{2}\right)$ and correlation of $\nu(\mathrm{O}-\mathrm{H})$ band intensity with the number of hydrogen atoms. See
} DOI: $10.1039 / \mathrm{b} 919977 \mathrm{~b}$
However, in practice, there are a number of underlying elementary reactions active which can conspire to moderate the syngas yields over extended periods of time. Cui et al. outline the following side reactions: ${ }^{7}$

$$
\begin{aligned}
2 \mathrm{CO} & \rightarrow \mathrm{C}+\mathrm{CO}_{2} \\
\mathrm{CO}_{2}+4 \mathrm{H}_{2} & \rightarrow \mathrm{CH}_{4}+2 \mathrm{H}_{2} \mathrm{O} \\
\mathrm{CO}+3 \mathrm{H}_{2} & \rightarrow \mathrm{CH}_{4}+\mathrm{H}_{2} \mathrm{O} \\
\mathrm{CO}+\mathrm{H}_{2} & \rightarrow \mathrm{C}+\mathrm{H}_{2} \mathrm{O} \\
\mathrm{CO}_{2}+\mathrm{H}_{2} & \rightarrow \mathrm{CO}+\mathrm{H}_{2} \mathrm{O} \\
\mathrm{CH}_{4} & \rightarrow \mathrm{C}+2 \mathrm{H}_{2}
\end{aligned}
$$

These include methanation ((3) and (4)) and reverse water gas shift (6) reactions. In addition, the Boudouard reaction (2), the $\mathrm{CO} / \mathrm{H}_{2}$ reduction reaction (5) and methane dissociation (7) can all result in the formation of surface carbon, which can lead to significant problems with catalyst deactivation. ${ }^{8}$ The extent of carbon retention by the reforming catalyst can be analysed by a number of means, with temperature programmed oxidation (TPO) finding wide application. ${ }^{9}$ However, it is much more difficult to determine the degree to which these catalysts retain hydrogen. In order to be able to further develop reaction schemes and mechanisms that attempt to describe the global transformation process (including a variety of surface mediated reactions not described in eqn (1)-(7)), it is important to be able to both identify and quantify how hydrogen is being partitioned within the adsorption/reaction system. An improved awareness of the role of hydrogen in the encompassing surface chemistry is therefore a highly desirable objective in this economically very significant area of heterogeneous catalysis.

Inelastic neutron scattering (INS) is showing increasing promise in being able to analyse hydrogenous moieties in heterogeneous catalysis. ${ }^{10,11}$ Due to hydrogen exhibiting an anomalously high neutron scattering cross section $\left(82 \mathrm{Barn}^{12}\right)$, the INS spectrum of the actual catalyst can be relatively featureless, whilst hydrogenous species are accentuated. Although the spectral resolution is rarely as good as that achievable by infrared or Raman spectroscopy, INS does provide access to a wide spectral range not often accessible in the application of optical techniques to probe catalytic systems. For example, alumina, ubiquitous in heterogeneous catalysis, ${ }^{13}$ strongly absorbs infrared radiation below approximately $1200 \mathrm{~cm}^{-1},{ }^{14}$ which results in an effective 'cut-off' at that energy; ${ }^{15}$ whereas certain INS spectrometers can 
provide access to the range $50-4000 \mathrm{~cm}^{-1} \cdot 14,16,17$ In this manner the INS spectrum can provide information on vibrational modes of species retained on alumina containing catalysts over an extended dynamic range compared to the more conventional infrared spectroscopic methods such as DRIFTS. ${ }^{15}$ Moreover, it is common for working heterogeneous catalysts to be black or dark in colour, which can cause problems in optical spectroscopy. Neutrons are not hindered by such absorptions due to the relative transparency of the substrate to the incident neutron flux.

Although INS lacks the sensitivity of infrared spectroscopy, it does have the additional advantage that spectral intensity is not complicated by electro-optical selection rules or issues such as dipole coupling. ${ }^{11}$ Instead, band intensities in INS are dominated simply by the number density of oscillators and the amplitude of motion of those particular oscillations. ${ }^{11,18}$ In principle this means that, within the inherent constraints of modest resolution in the vibrational region of the spectrum (e.g. $10-20 \mathrm{~cm}^{-1}$ ), INS should be able to speciate surface entities at catalyst surfaces and also to quantify them. Whereas the former is becoming more prevalent, ${ }^{10,19}$ somewhat surprisingly, there are very few studies on the use of neutrons to determine concentration data for retained species at catalyst surfaces. Noticeable exceptions are the work of Koon, ${ }^{20,21}$ Acharya et al., ${ }^{22}$ Mitchell and Tomkinson ${ }^{23}$ and Albers et al. ${ }^{24,25}$ Rather innovatively, Koon used a portable neutron source to determine the $\mathrm{C}$ : $\mathrm{H}$ ratio for coke deposits found on a chromia-alumina catalyst that have been used in the dehydrogenation of 1-butene. That work reports a $\mathrm{C}: \mathrm{H}$ value of ca. 2.7. ${ }^{21}$ Acharya et al. used small angle neutron scattering (SANS) to characterise a silica-alumina catalyst after coke deposition had occurred during the isomerisation of xylenes. These SANS measurements not only provided information on the $\mathrm{C}: \mathrm{H}$ ratio $(\mathrm{ca} .3 .3: 1)$ but also provided information on where coke was deposited within the catalyst pore network. ${ }^{22}$ Mitchell and Tomkinson used INS to study hydroxylated molybdate on goethite and hydrated molybdate on alumina catalysts. Interestingly, they established that INS could provide a direct spectroscopic means of estimating surface concentrations of hydroxylic species. ${ }^{23}$ More recently, Albers et al. used INS to analyse a variety of catalyst cokes containing varying degrees of hydrogen. ${ }^{24} \mathrm{~A}$ subsequent study from the same team correlated the area of $\mathrm{C}-\mathrm{H}$ bending bands with hydrogen content for a number of activated carbon catalyst support materials. ${ }^{25}$ Whilst that work utilised the quantitative aspect of INS to characterise a series of materials used in catalyst preparative procedures, the work presented here seeks to use INS to obtain a quantitative assessment of surface species formed during the course of a reaction over a representative supported metal catalyst. Specifically, it examines an alumina-supported nickel methane reforming catalyst that has been operated at steady state in the methane 'dry' reforming reaction. A process environment that would lead to carbon laydown has deliberately been selected, including a relatively high nickel loading and a methane-rich reaction mixture. Subsequent work is focusing on catalysts with a lower nickel loading. By application of simple calibration procedures, the density of hydrocarbonaceous and hydroxyl species retained by the catalyst have been determined. Furthermore, parallel
TPO measurements are used to determine total carbon retention. In this way, the extent of carbon deposition plus the number of surface $\mathrm{C}-\mathrm{H}$ and $\mathrm{O}-\mathrm{H}$ entities has been evaluated. Importantly, the methodology outlined is generic and should be applicable to a wide number of heterogeneously catalysed reaction systems.

\section{Experimental}

\subsection{Catalyst preparation}

A $45 \% \mathrm{w} / \mathrm{w} \mathrm{Ni} / \mathrm{Al}_{2} \mathrm{O}_{3}$ catalyst was prepared by wet impregnation of $\alpha$-alumina (Sumitomo Chemical, BET surface area $1.93 \mathrm{~m}^{2} \mathrm{~g}^{-1}$ ) with nickel nitrate hexahydrate (BDH, 98\%). Specifically, nickel nitrate was dissolved in a minimal amount of water to which alumina was added. Water was driven off the suspension using a hot plate, before drying in an oven at $393 \mathrm{~K}$ for 6 days. The resulting material was then calcined in static air by heating to $773 \mathrm{~K}$ at $1 \mathrm{~K} \mathrm{~min}^{-1}$, then to $1173 \mathrm{~K}$ at $5 \mathrm{~K} \mathrm{~min}^{-1}$. The temperature was maintained for one hour before cooling to room temperature at $10 \mathrm{~K} \mathrm{~min}^{-1}$.

\subsection{Reaction testing}

A known mass of catalyst was loaded into a quartz U-tube reactor and capped with a quartz wool plug. The catalyst was heated to $1023 \mathrm{~K}$ under flowing $\mathrm{He}\left(1250 \mathrm{ml} \mathrm{min}^{-1}\right)$ and $\mathrm{H}_{2}$ $\left(140 \mathrm{ml} \mathrm{min}^{-1}\right)$ with the consumption of hydrogen monitored by an on-line quadrupole mass spectrometer (Spectra Microvision plus). Once hydrogen consumption was complete, signifying reduction of the nickel particles, the reaction was initiated by passing $\mathrm{CO}_{2}\left(35 \mathrm{ml} \mathrm{min}{ }^{-1}\right)$ and $\mathrm{CH}_{4}\left(70 \mathrm{ml} \mathrm{min}{ }^{-1}\right)$ over the catalyst at $1073 \mathrm{~K}$. This represents a $\mathrm{CH}_{4}: \mathrm{CO}_{2}$ ratio of $2: 1$ rather than the $1: 1$ ratio indicated by eqn (1). A higher methane component was selected in order to emphasize the hydrocarbon laydown process during conditions which still favour the forward reaction. Reaction was maintained under these conditions for $6 \mathrm{~h}$, with the mass spectrometer showing a high hydrogen yield. After this time the reaction was 'quenched' by stopping the heating and allowing the catalyst to cool to ambient temperatures under flowing helium. The reactor was then isolated and transferred to an indiumsealed gas tight aluminium sample cell inside an argon-filled glove box (MBraun UniLab MB-20-G, $\left[\mathrm{H}_{2} \mathrm{O}\right]<1 \mathrm{ppm}$, $\left.\left[\mathrm{O}_{2}\right]<2 \mathrm{ppm}\right)$. This cell was then transferred to the INS spectrometer, where INS spectra were recorded at $20 \mathrm{~K}$.

\subsection{INS measurements}

INS spectra were recorded using the MAPS spectrometer that is located at the ISIS Facility, Rutherford Appleton Laboratory. ${ }^{17}$ It is a direct geometry chopper instrument that was operated at an incident energy of $4840 \mathrm{~cm}^{-1}$. This energy was chosen as it provides access to the important $\mathrm{C}-\mathrm{H}$ and $\mathrm{O}-\mathrm{H}$ stretching region of the vibrational spectrum. After spectral acquisition, samples were retained for elemental analysis, which was performed using a CE 440 Elemental Analyser (Exeter Analytical Inc.).

The following three compounds were used as external calibrants: polystyrene $\left(\left[-\mathrm{CH}_{2} \mathrm{CH}\left(\mathrm{C}_{6} \mathrm{H}_{5}\right)-\right]_{n}\right.$, Aldrich, gel permeation chromatography standard, powder, typical molecular 
weight $=29300$ ), brucite (magnesium hydroxide, $\mathrm{Mg}(\mathrm{OH})_{2}$, Fluka, $>99 \%$ ) and talc (hydrous magnesium silicate, $3 \mathrm{MgO}$. $4 \mathrm{SiO}_{2} \cdot \mathrm{H}_{2} \mathrm{O}$, Fluka, Ph. Eur.). The polystyrene provided a reference for $(\mathrm{C}-\mathrm{H})$ stretching modes, whilst the brucite and talc provided reference spectra for compounds for (O-H) stretching modes. Known masses of these compounds were loaded into sachets made from aluminium foil, which were contained within aluminium sample holders, then the spectra recorded. In this manner the INS spectra could be directly correlated with the mass of the reference material. As with the catalyst measurements, spectral acquisition was performed at $20 \mathrm{~K}$.

\subsection{Temperature programmed oxidation}

Temperature programmed oxidation (TPO) of the catalyst post-reaction was carried out on custom-built apparatus using a quadrupole mass spectrometer (Leda Mass (Spectra) Gas Analyser, LM22). Approximately $30 \mathrm{mg}$ of catalyst was placed between quartz wool plugs in a $1 / 4^{\prime \prime}$ o.d. stainless steel tube within a programmable oven (Neytech 25PAF). The sample was heated at $10 \mathrm{~K} \mathrm{~min}^{-1}$ to $1173 \mathrm{~K}$ under a $40 \mathrm{ml} \mathrm{min} \mathrm{m}^{-1}$ flow of $5 \% \mathrm{O}_{2}$ in He. Quantification of the extent of carbon present in the spent catalyst was made with reference to calibration plots prepared using the oxidation of graphite, as well as the thermal decomposition of calcium carbonate.

\section{Results and discussion}

\subsection{Basis of the method and calibration measurements}

One of the difficulties of using infrared spectroscopy for quantitative analysis is that the extinction coefficient of any mode is specific to a given molecule. This means that it is not possible to transfer extinction coefficients between molecules: each molecule must be individually calibrated. For adsorbed species on surfaces this is rarely possible and is meaningless when there are a mixture of species present. The problem arises because the infrared intensity is determined by the interaction of electromagnetic radiation with the electrons; since the electronic structure of a molecule is unique, it follows that the intensities will be specific to that molecule. This problem does not occur in INS spectroscopy since the interaction of the neutron is with the atomic nucleus; the electrons are irrelevant. The observed intensity of an INS spectral band, $S$, is a function of both the energy, $\omega\left(\mathrm{cm}^{-1}\right)$, and the momentum, $Q(\AA)$, exchanged during the scattering process and is given by: ${ }^{11}$

$$
S\left(Q, \omega_{i}\right) \propto\left(Q U_{i}\right)^{2} \exp \left(-\left(Q U_{\mathrm{Tot}}\right)^{2}\right) \sigma
$$

Where $\omega_{i}$ is the $i$ th mode at wavenumber $\omega, U_{i}$ is the root mean square displacement of the atoms in the mode, $U_{\text {Tot }}$ is the total root mean square displacement of all the atoms in all the modes, both internal and external, $\sigma$ is the inelastic scattering cross section of the atom. The momentum transfer is an experimental variable and the cross section is a fundamental property so only the amplitude of vibration is a molecular property. If we make the assumption that the
$\mathrm{O}-\mathrm{H}$ stretch can be treated as a harmonic oscillator, then the amplitude of vibration is given by:

$$
\left(U_{i}\right)^{2}=\frac{\hbar^{2}}{2 \mu \omega_{i}}
$$

Where $\mu$ is the reduced mass of the oscillator. Thus the amplitude of vibration depends only on the transition energy and is independent of the molecular entity. From (9) it can be seen that the Debye-Waller factor (the exponential term) in (8) is dominated by the low energy modes, since a surface species and the model compounds have many of these, the DebyeWaller factors will be similar. The result is that a calibration is transferable between similar species.

Polystyrene $\left(\left[-\mathrm{CH}_{2} \mathrm{CH}\left(\mathrm{C}_{6} \mathrm{H}_{5}\right)-\right]_{n}\right)$ was chosen as a readily available reference material, with the presence of two types of hydrogen, aliphatic $\left(\sim 2900 \mathrm{~cm}^{-1}\right)$ and aromatic $\left(\sim 3100 \mathrm{~cm}^{-1}\right)$, providing a useful resolution test for the instrument. Since the two types of hydrogen differ in energy by only $200 \mathrm{~cm}^{-1}$, from (9) it can be seen that the difference in $U_{i}$ for the two types of hydrogen is only $\sim 2.5 \%$, which for these measurements is negligible. A high molecular weight variant (29 300) was used because the large $n$ mitigates the effect of terminal groups. In this way, the formula mass can be simplified to $\mathrm{C}_{6} \mathrm{H}_{5} \mathrm{C}_{2} \mathrm{H}_{3}$, which corresponds to 8 hydrogen atoms per monomeric subunit. Fig. 1(a) shows the INS spectrum for different masses of polystyrene recorded using the MAPS neutron spectrometer. $969 \mathrm{mg}$ of sample yields a single broad feature centred at $3000 \mathrm{~cm}^{-1}$ that is readily assigned to the $\mathrm{C}-\mathrm{H}$ stretching modes of polystyrene. The fact that the corresponding infrared spectrum contains a variety of discrete bands in this region ${ }^{26}$ demonstrates the reduced resolution accessible with this spectrometer arrangement. Nevertheless, the integrated intensity of this single peak represents the number of $\mathrm{CH}$ species present in the neutron beam. Reducing the mass of the polystyrene leads to a diminution of intensity of this feature. Somewhat surprisingly, and in contrast to the perception that INS is an insensitive technique, the single band is still discernible against the baseline when only $23 \mathrm{mg}$ of sample is present in the beam (Fig. 1(a) inset).

A plot of integrated intensity for the $\nu(\mathrm{C}-\mathrm{H})$ feature as a function of sample mass is presented in Fig. 1(b), which reveals a straight line with a correlation coefficient of $R=0.9995$. The slope of this line corresponds to the response factor for $\mathrm{C}-\mathrm{H}$ containing species examined using this spectrometer configuration. The linearity of the response is consistent with the observations of Albers et al. ${ }^{25}$ confirming the spectral response to be directly proportional to the number of hydrogen atoms present in the beam.

In order to gauge the spectral response for hydroxyl groups, a moiety commonly encountered in heterogeneous catalysis, ${ }^{14,27}$ two further standards were analysed. Fig. 2(a) shows the INS spectrum for different sample masses of brucite, $\left(\mathrm{Mg}(\mathrm{OH})_{2}\right)$, for which the formula mass affords 2 hydrogen atoms. The feature at $3650 \mathrm{~cm}^{-1}$ is assigned to the $\mathrm{O}-\mathrm{H}$ stretch of hydroxyl groups. In a similar manner to that encountered with polystyrene, the intensity of this feature decreases as a function of sample mass. The resulting calibration plot is shown in Fig. 2(b), where again peak intensity is shown to 

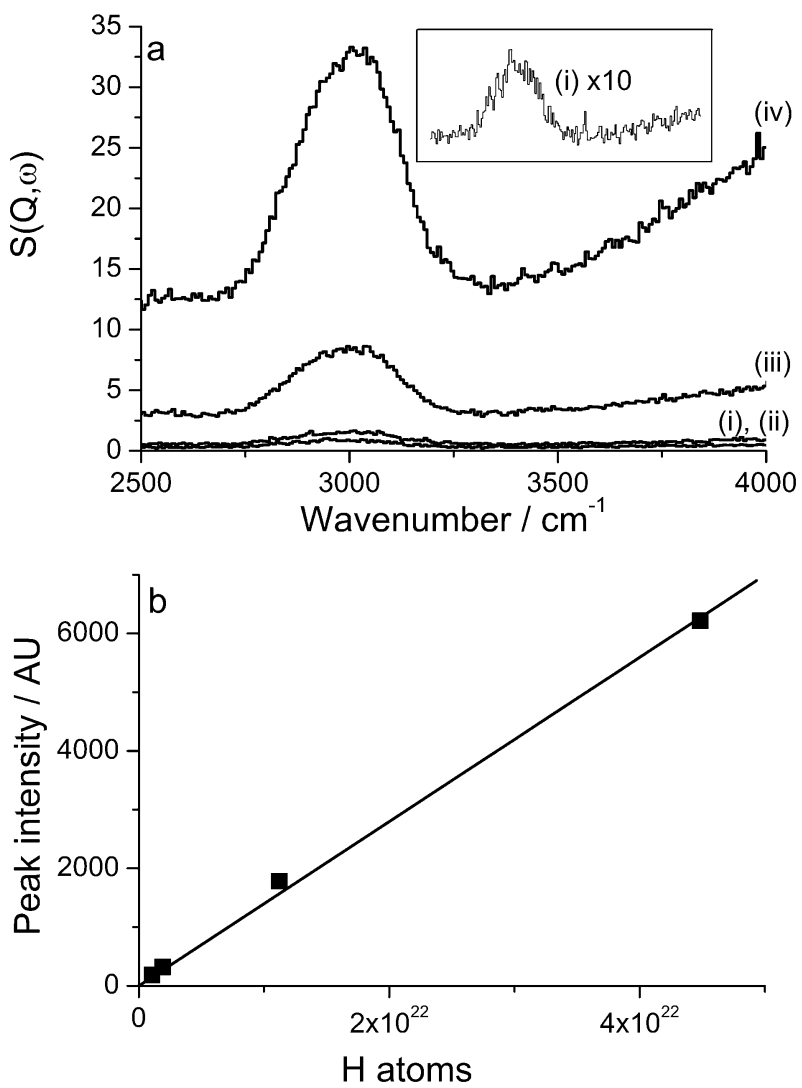

Fig. 1 (a) INS spectra of polystyrene in the region $2500-4000 \mathrm{~cm}^{-1}$ for four different masses of polystyrene: (i) $23 \mathrm{mg}$, (ii) $41 \mathrm{mg}$, (iii) $242 \mathrm{mg}$ and (iv) $969 \mathrm{mg}$. The inset represents sample (i) at a magnification of $10 \times$ compared to the main plot. (b) A plot of integrated band intensity of the $\nu(\mathrm{C}-\mathrm{H})$ mode of polystyrene as a function of the number of hydrogen atoms for a given mass. The straight line represents a linear least squares fit to the data (constrained through the origin), the slope of which defines the $\nu(\mathrm{C}-\mathrm{H})$ sensitivity factor for the spectrometer operating in this configuration.

be directly proportional to sample mass. The quality of the fit is not as good as with the hydrocarbon $(R=0.9680)$, nevertheless, it is clear from this plot that the trend is linear and that INS is capable of detecting precise amounts of hydroxyl groups as well as $\mathrm{CH}$ entities. In order to evaluate the degree of error inherent in making these absolute measurements, triplicate measurements were made for a brucite sample mass of $152 \pm 1 \mathrm{mg}$. These measurements involved new samples in new sachets. The data points are contained within a standard deviation of $\pm 6.2 \%$, indicating a good degree of precision within these measurements.

A similar approach was explored using talc (hydrous magnesium silicate) as an additional external calibrant for the $\nu(\mathrm{O}-\mathrm{H})$ scattering intensity, with the resulting spectra and correlation plot presented as ESI. $\dagger$ Briefly, the trends observed with brucite are essentially repeated with the talc measurements, confirming the validity of the approach adopted.

\subsection{INS spectrum}

The INS spectrum in the range $2500-4000 \mathrm{~cm}^{-1}$ of the $45 \%$ $\mathrm{Ni} / \mathrm{Al}_{2} \mathrm{O}_{3}$ catalyst post-reaction is presented in Fig. 3. The spectrum is characterised by the presence of two features: a
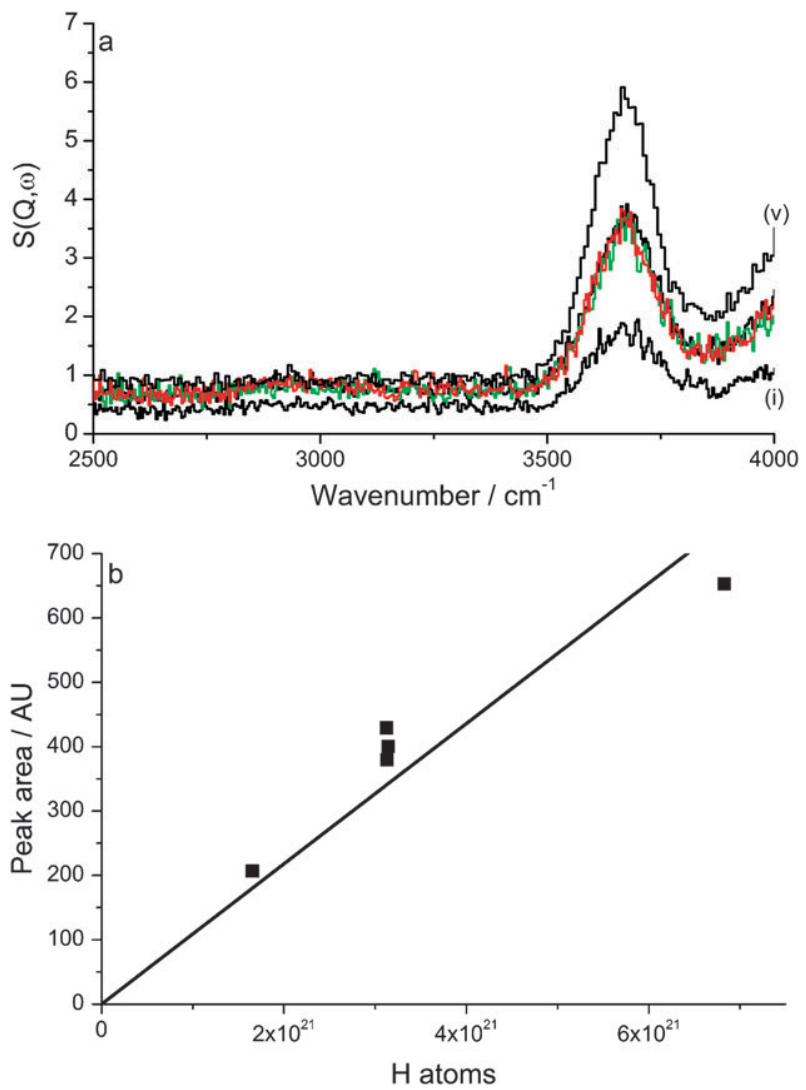

Fig. 2 (a) INS spectra of brucite $\left(\mathrm{Mg}(\mathrm{OH})_{2}\right)$ in the region 2500-4000 $\mathrm{cm}^{-1}$ for five different masses of brucite: (i) $80 \mathrm{mg}$, (ii) $152 \mathrm{mg}$, (iii) $152 \mathrm{mg}$, (iv) $152 \mathrm{mg}$, and (v) $330 \mathrm{mg}$. The $\sim 150 \mathrm{mg}$ sample was performed in triplicate as a guide for the errors inherent to the determination of absolute peak intensities. (b) A plot of integrated band intensity of the $\nu(\mathrm{O}-\mathrm{H})$ mode of brucite as a function of the number of hydrogen atoms for a given mass. The straight line represents a linear least squares fit to the data (constrained through the origin), the slope of which defines the $\nu(\mathrm{O}-\mathrm{H})$ sensitivity factor for the spectrometer operating in this configuration.

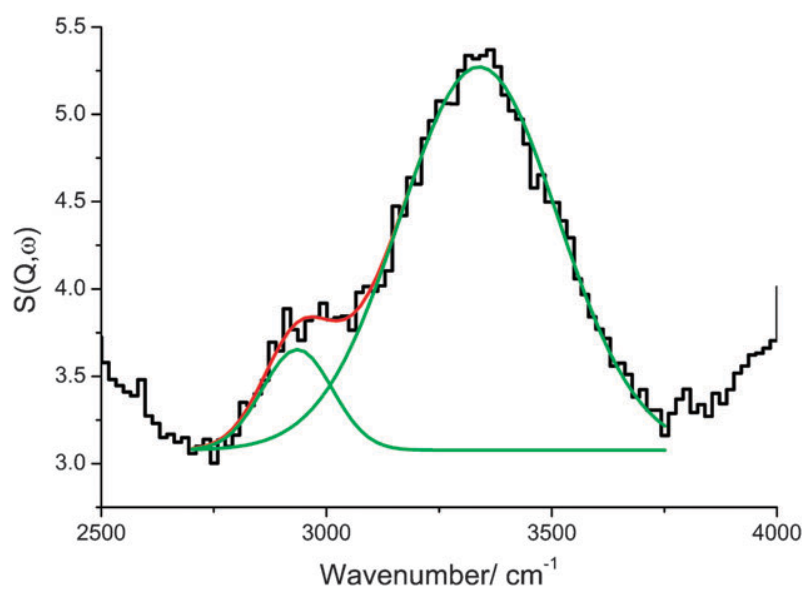

Fig. 3 The INS spectrum $\left(2500-4000 \mathrm{~cm}^{-1}\right)$ of the $45 \% \mathrm{Ni} / \mathrm{Al}_{2} \mathrm{O}_{3}$ catalyst after undergoing 'dry' reforming of methane at $1073 \mathrm{~K}$ for 6 hours. The experimental data are well described by a combination of two Gaussian curves (green lines) centred at 2935 and $3339 \mathrm{~cm}^{-1}$, which are obtained from a non-linear least squares fitting procedure. The solid red line represents the overall fit. 
minor peak centred about $3000 \mathrm{~cm}^{-1}$ and a dominant band centred at $3400 \mathrm{~cm}^{-1}$.

The $3000 \mathrm{~cm}^{-1}$ is assigned to the $\mathrm{C}-\mathrm{H}$ stretching mode of a small concentration of hydrocarbon species. There is a hint that the $3000 \mathrm{~cm}^{-1}$ peak is comprised of two parts, with maxima at approximately 2950 and $3020 \mathrm{~cm}^{-1}$, corresponding, respectively, to $\nu(\mathrm{C}-\mathrm{H})$ modes of aliphatic and olefinic/aromatic hydrocarbon species. Unfortunately, the limited resolution and low signal/noise ratio restrict a reliable determination of the relative quantities of these two species. Nevertheless, it is apparent from the peak width and shape of the low wavenumber feature in Fig. 3 that a hydrocarbonaceous component is present and that it comprises both aliphatic and olefinic/ aromatic moieties. The $3400 \mathrm{~cm}^{-1}$ band represents the $\mathrm{O}-\mathrm{H}$ stretch of hydroxyl groups, most probably present on the surface of the $\alpha$-alumina support material.

The relatively low scattering intensity apparent in Fig. 3 indicates the quantity of retained hydrogenous species to be low. This is entirely consistent with the hydrogen analysis of the post-reaction sample where duplicate measurements indicated no hydrogen to be detectable, with the detection limit of the apparatus estimated to be $<0.3 \%$. Whereas quantification of hydrogen present on 'dry' reforming methane catalysts is unreported, there are a few reports on the relative quantity of hydrogen associated with the overlayers on supported metal catalysts. For instance, in addition to Koon, ${ }^{21}$ Pieck et al. looked at the coke deposited during the reforming of naphtha on $\mathrm{Pt}-\mathrm{Re} / \mathrm{Al}_{2} \mathrm{O}_{3}$ catalysts and considered two types of carbonaceous deposits: one deposited on the metal with a $\mathrm{C}: \mathrm{H}$ ratio $c a .1$ and the other deposited on the support with a $\mathrm{C}: \mathrm{H}$ ratio of about $2 .{ }^{4}$ Against this background, it is very desirable to be able to examine the case for nickel catalysts applied to the $\mathrm{CO}_{2}$ methane reforming reaction, where INS can indeed make an impact.

The spectrum in Fig. 3 can be readily de-convoluted into the sum of two Gaussians using non-linear least squares analysis (OriginLab Origin v.6.1). By the application of response factors obtained from Fig. 1(b) and 2(b), integration of peaks centred at 2935 and $3339 \mathrm{~cm}^{-1}$ can then be transformed into hydrogen concentrations for, respectively, the $\mathrm{C}-\mathrm{H}$ and $\mathrm{O}-\mathrm{H}$ bands. In this manner, the quantity of retained $\mathrm{C}-\mathrm{H}$ species

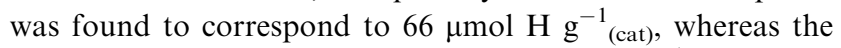
$\mathrm{O}-\mathrm{H}$ species corresponded to $728 \mu \mathrm{mol} \mathrm{H} \mathrm{g}^{-1}$ (cat). These values are exceptionally low and indicate minimal retention of hydrogen by the catalyst under the specified reaction conditions. This is the first time that these values have been obtained for a nickel-based catalyst operating in this way. Knowing the (low) extent of hydrogen retention by the catalyst enables the relative importance of various side reactions to the overall transformation of methane into 'syngas', eqn (1), to be evaluated.

\subsection{Temperature programmed oxidation}

The TPO profile for the $\mathrm{Ni} / \mathrm{Al}_{2} \mathrm{O}_{3}$ catalyst post-reaction is presented in Fig. 4 and is characterised by an intense, nearly symmetric feature centred at $870 \mathrm{~K}$. This temperature is well below that reported for graphite $\left(1035 \mathrm{~K}^{28}\right)$ and is consistent with the presence of amorphous carbon or 'coke'. ${ }^{28,29}$ Integration of

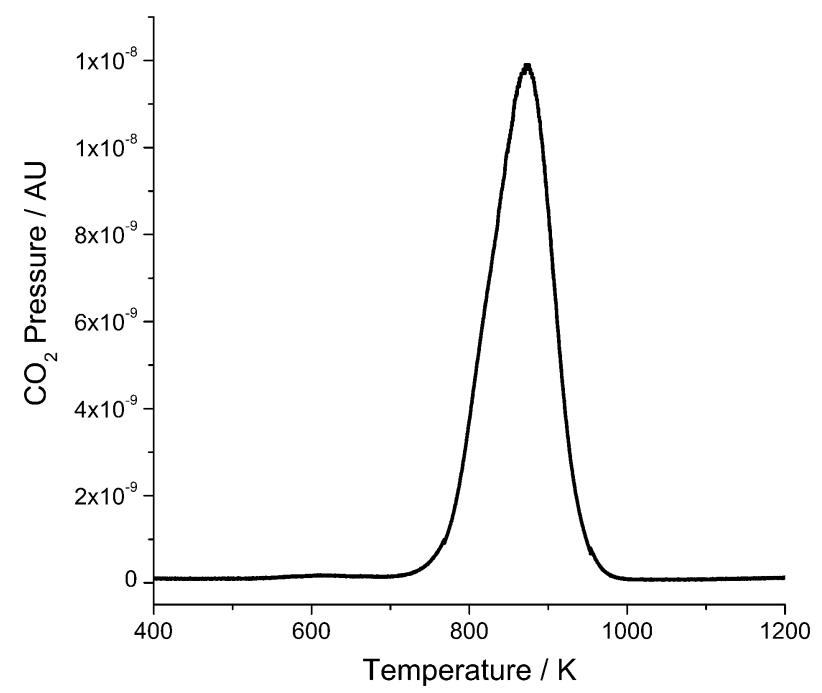

Fig. 4 A temperature programmed oxidation profile for the $45 \%$ $\mathrm{Ni} / \mathrm{Al}_{2} \mathrm{O}_{3}$ catalyst post-reaction after undergoing 'dry' reforming of methane at $1073 \mathrm{~K}$ for 6 hours.

the peak in Fig. 4 corresponds to $11.3 \mathrm{mmol} \mathrm{C} \mathrm{g}^{-1}$ (cat) of spent catalyst. This corresponds to the catalyst extracted from INS reactor having a carbon loading of $13.6 \%$, which is substantial and indicates carbon laydown to be an active pathway, indicating a clear role for one or more of eqn (2), (5) and (7) in the overall surface chemistry. In principle the presence of a water signal in the TPO profile can be used to indicate the quantities of retained hydrogen. However, no water is detected in the post-reaction TPO experiments. This is consistent with the retained hydrogen, as measured by INS, being below the detection limits of the TPO technique. Interestingly, the TPO data clearly show that the degree of carbon laydown dwarfs that of hydrogen retention, indicating that not all chemical pathways potentially accessible in the 'dry' reforming process (e.g. eqn (1)-(7)) have equal weighting.

\section{Discussion}

This analysis is producing new information that is providing some insight as to the complexity inherent in this non-trivial reaction between methane and carbon dioxide over a nickel catalyst. The total carbon content by TPO is $11.3 \mathrm{mmol} \mathrm{C} \mathrm{g}^{-1}$ (cat), whereas the total hydrogen content (as represented by $\nu(\mathrm{C}-\mathrm{H})$ and

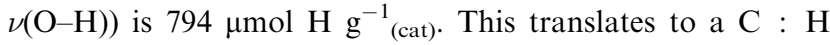
ratio of $14: 1$, which significantly exceeds that reported in other studies of coked catalysts where the overlayer is associated with polycyclic aromatic compounds. ${ }^{21,30}$ Moreover, if one considers solely the $\mathrm{C}: \mathrm{H}$ ratio for hydrogen associated with carbon, then the ratio increases dramatically to $171: 1$. The magnitude of the $\mathrm{C}: \mathrm{H}$ values observed here massively exceed that anticipated for discrete hydrocarbon species (e.g. ca. $\left.2: 1^{4}\right)$ and are therefore thought to indicate the presence of at least two types of carbon: (i) a minority species present at the metal surface that is associated with hydrogen (as evidenced by $\nu(\mathrm{C}-\mathrm{H})$ in Fig. 3) and (ii) a majority species that contains negligible hydrogen and which is the major contributor to the TPO profile (Fig. 4). This latter species is assigned to amorphous carbon. Unfortunately, due 
to the limited resolution of the spectrum in Fig. 3, it is not possible to discern the molecular form of the hydrocarbonaceous overlayer. Refinements to the INS measurements are currently being explored, in an attempt to obtain more precise information on how hydrogen is bound to carbon at the catalyst surface. This action represents 'work in progress'.

The hydrogen content attributed to hydroxyl groups is $728 \mu \mathrm{mol} \mathrm{H} \mathrm{g}{ }^{-1}$ (cat) and this exceeds the hydrocarbonaceous contribution by a factor of 11 . It is thought likely that the hydroxyl population is associated with the support material. Hydroxyl groups are implicated in mechanisms for both steam and $\mathrm{CO}_{2}$ methane reforming reactions, although agreement over their mechanistic role in the 'dry' reforming reaction remains a topic of some debate. ${ }^{31}$

Whilst these INS experiments inevitably raise further issues concerning the complexity of the reforming process, they do give added insight as to how hydrogen is being partitioned within the retained overlayer. Not least, it indicates how efficient the catalyst is at cycling hydrogen and that carbon deposition is more significant than processes that lead to hydrogen retention. Finally, we note that the methodology described herein is generic and should be applicable to a wide number of heterogeneously catalysed systems.

\section{Conclusions}

INS and TPO measurements have been used to characterise a $45 \% \mathrm{Ni} / \mathrm{Al}_{2} \mathrm{O}_{3}$ catalyst after $6 \mathrm{~h}$ 'dry' reforming at $1073 \mathrm{~K}$. The main results can be summarised as follows:

- The INS spectrum indicates the presence of hydrocarbon species plus hydroxyl groups to be present at the catalyst surface after reaction. The hydrocarbon component is made up of aliphatic as well as olefinic/aromatic moieties.

- By using external reference materials as calibrants, the quantities of hydrogen associated with the surface hydrocarbon

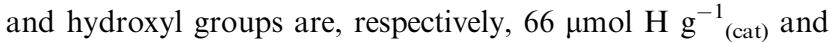

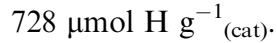

- TPO measurements show the quantity of retained carbon to be $11.3 \mathrm{mmol} \mathrm{C}^{-1}$ (cat), which represents a carbon loading of $13.6 \%$.

- The overall $\mathrm{C}: \mathrm{H}$ ratio for this catalyst is $14: 1$ but rises to 171 : 1 if one discounts hydrogen present as hydroxyl groups. The magnitude of these numbers suggests the presence of at least two types of carbon: (i) a minority hydrocarbonaceous species present at the metal surface and (ii) a majority species of amorphous carbon.

- The catalyst is very efficient at cycling hydrogen, less so at cycling carbon.

\section{Acknowledgements}

The authors would like to thank the EPSRC for overall funding (Grant EP/E028861/1) and the Rutherford Appleton Laboratory for access to neutron beam facilities.

\section{References}

1 I. Chorkendorff and J. W. Niemantsverdriet, Concepts of Modern Catalysis and Kinetics, Wiley VCH, Weinheim, 2003, ch. 8, pp. 301-309.

2 J. Wei and E. Iglesia, Angew. Chem., Int. Ed., 2004, 43, 3685-3688; J. M. Zalc, W. H. Green and E. Iglesia, Ind. Eng. Chem. Res., 2006, 45, 2677-2688.

3 D. L. Trimm, Catal. Today, 1997, 37, 233-238.

4 C. L. Pieck, E. L. Jablonski, J. M. Parera, R. Frety and F. Lefebvre, Ind. Eng. Chem. Res., 1992, 31, 1017-1021.

5 J. Xu and C. H. Bartholomew, J. Phys. Chem. B, 2005, 109, $2392-2403$.

6 M. C. J. Bradford and A. M. Vannice, Appl. Catal., A, 1996, 142, 73-96.

7 Y. Cui, H. Zhang, H. Xu and W. Li, Appl. Catal., A, 2007, 318, 79-88.

8 C. H. Bartholomew, Appl. Catal., A, 2001, 212, 17-60.

9 C. A. Querini and S. C. Fung, Catal. Today, 1997, 37, 277-283; Z. L. Zhang and X. E. Verykios, Catal. Today, 1994, 21, 589-595; C. M. Finnerty, N. J. Coe, R. H. Cunningham and R. M. Ormerod, Catal. Today, 1998, 46, 137-145.

10 P. Albers, H. Angert, G. Prescher, K. Seibold and S. F. Parker, Chem. Commun., 1999, 1619-1620; D. Lennon, J. McNamara, J. R. Philips, R. M. Ibberson and S. F. Parker, Phys. Chem. Chem. Phys., 2000, 2, 4447-4451.

11 P. C. H. Mitchell, S. F. Parker, A. J. Ramirez-Cuesta and J. Tomkinson, Vibrational spectroscopy with neutrons, World Scientific, Singapore, 2005.

12 V. F. Sears, Neutron News, 1992, 3, 26-37.

13 S. C. N. Satterfield, Heterogeneous Catalysis in Industrial Practice, Krieger Publishing, Malabar, 2nd edn, 1996.

14 A. Mcinroy, D. Lundie, J. Winfield, C. Dudman, P. Jones, S. Parker and D. Lennon, Catal. Today, 2006, 114, 403-411.

15 A. R. McInroy, D. T. Lundie, J. M. Winfield, C. C. Dudman, P. Jones, S. F. Parker, J. W. Taylor and D. Lennon, Phys. Chem. Chem. Phys., 2005, 7, 3093-3101.

16 D. Colognesi, M. Celli, F. Cilloco, R. J. Newport, S. F. Parker, R. V. Albertini, F. Sacchetti, J. Tomkinson and M. Zoppi, Appl. Phys. A: Solid Surf., 2002, 74, S64-S66.

$17 \mathrm{http}: / /$ www/isis.ral.ac.uk/excitations/maps/maps.htm.

18 A. Ramirez-Cuesta, Comput. Phys. Commun., 2004, 157, 226-238.

19 P. W. Albers and S. F. Parker, Adv. Catal., 2007, 51, 99-132.

20 C. Koon, J. Catal., 1989, 120, 484-486.

21 C. Koon, J. Catal., 1990, 126, 306-310.

22 D. R. Acharya, A. J. Allen and R. Hughes, Ind. Eng. Chem. Res., 1990, 29, 1119-1125.

23 P. C. H. Mitchell and J. Tomkinson, Catal. Today, 1991, 9, 227-235.

24 P. Albers, S. Bösing, G. Prescher, K. Siebold, D. K. Ross and S. F. Parker, Appl. Catal., A, 1999, 187, 233-243.

25 P. W. Albers, J. Pietsch, J. Krauter and S. F. Parker, Phys. Chem. Chem. Phys., 2003, 5, 1941-1949.

26 A. T. Todorovskii and S. Ya. Plotkin, J. Appl. Spectrosc., 1989, 51, 1050-1055.

27 D. Uy, A. Dubkov, G. W. Graham and W. H. Weber, Catal. Lett., $2000,68,25-32$.

28 P. Wang, E. Tanabe, K. Ito, J. Jia, H. Morioka, T. Shishido and K. Takehira, Appl. Catal., A, 2002, 231, 35-44.

29 X. Zhu, Y. P. Zhang and C. J. Liu, Catal. Lett., 2007, 118, 306-312.

30 D. L. Trimm, Chem. Eng. Process., 1984, 18, 137-148.

31 H. S. Bengaard, J. K. Nørskov, J. Sehested, B. S. Clausen, L. P. Nielsen, A. M. Molenbroek and J. R. Rostrup-Nielsen, J. Catal., 2002, 209, 365-384; M. C. J. Bradford and A. M. Vannice, Appl. Catal., A, 1996, 142, 97-122; P. Ferreira-Aparicio, M. Fernandez-Garcia, A. Guerrero-Ruiz and I. Rodríguez-Ramos, J. Catal., 2000, 190, 296-308; P. Ferreira-Aparicio, I. Rodríguez, J. A. Anderson and A. Geuerrero-Ruiz, Appl. Catal., A, 2000, 202, 183-196. 